\title{
Correction to: A Population-Based Analysis of Long-Term Outcomes Among Older Adults Requiring Unexpected Intensive Care Unit Admission After Cancer Surgery
}

\author{
Bourke W. Tillmann, MD ${ }^{1,2,3}$ (1) , Julie Hallet, $\mathrm{MD}^{3,4,5,6,7}$, Matthew P. Guttman, $\mathrm{MD}^{3,4}$, Natalie Coburn, $\mathrm{MD}^{3,4,5,6,7}$, \\ Tyler Chesney, $\mathrm{MD}^{4,8}$, Jesse Zuckerman, $\mathrm{MD}^{3,4}$, Alyson Mahar, $\mathrm{PhD}^{9}$, Victoria Zuk, MHSc ${ }^{7}$, \\ Wing C. Chan, $\mathrm{MPH}^{6}$, Barbara Haas, $\mathrm{MD}^{1,2,3,4,5,6,7}$, and members of the REcovery after Surgical Therapy for \\ Older adults Research-Cancer (RESTORE-C) group \\ ${ }^{1}$ Interdepartmental Division of Critical Care, University of Toronto, Toronto, ON, Canada; ${ }^{2}$ Department of Critical Care \\ Medicine, Sunnybrook Health Sciences Centre, Toronto, ON, Canada; ${ }^{3}$ Institute of Health Policy, Management, and \\ Evaluation, University of Toronto, Toronto, ON, Canada; ${ }^{4}$ Department of Surgery, University of Toronto, Toronto, ON, \\ Canada; ${ }^{5}$ Department of Surgery, Sunnybrook Health Sciences Centre, Toronto, ON, Canada; ${ }^{6}$ ICES, Toronto, ON, \\ Canada; ${ }^{7}$ Clinical Evaluative Sciences, Sunnybrook Research Institute, Toronto, ON, Canada; ${ }^{8}$ Department of Surgery, \\ Unity Health, Toronto, ON, Canada; ${ }^{9}$ Department of Community Health Sciences, University of Manitoba, Winnipeg, \\ Manitoba, Canada
}

CORRECTION TO: ANN SURG ONCOL (2021) 28:7014-7024 HTTPS://DOI.ORG/10.1245/S10434-021-10705-8

In the original online version of this article, Wing C. Chan's family name was misspelled. The original article was corrected.
Publisher's Note Springer Nature remains neutral with regard to jurisdictional claims in published maps and institutional affiliations.

The original article can be found online at https://doi.org/10.1245/ s10434-021-10705-8.

(C) Society of Surgical Oncology 2021

Published online: 24 November 2021

B. W. Tillmann, MD

e-mail: Bourke.tillmann@sunnybrook.ca 